rh 19 Revue d'histoire du XIXe siècle

Société d'histoire de la révolution de 1848 et des

révolutions du XIXe siècle

$24 \mid 2002$

Varia

Georgios VAROUXAKIS, Victorian Political Thought on France and the French

Basingstoke, Palgrave, 2002, 223 p.

Fabrice Bensimon

\title{
OpenEdition
}

Journals

Édition électronique

URL : http://journals.openedition.org/rh19/380

DOI : $10.4000 /$ rh 19.380

ISSN : $1777-5329$

Éditeur

La Société de 1848

Édition imprimée

Date de publication : 1 juin 2002

Pagination : 169-172

ISSN : 1265-1354

Référence électronique

Fabrice Bensimon, «Georgios VAROUXAKIS, Victorian Political Thought on France and the French », Revue d'histoire du XIXe siècle [En ligne], 24 | 2002, mis en ligne le 04 juin 2003, consulté le 22 septembre 2020. URL : http://journals.openedition.org/rh19/380 ; DOI : https://doi.org/10.4000/ rh19.380

Ce document a été généré automatiquement le 22 septembre 2020.

Tous droits réservés 


\section{Georgios VAROUXAKIS, Victorian Political Thought on France and the French}

Basingstoke, Palgrave, 2002, 223 p.

Fabrice Bensimon

Au XIX ${ }^{e}$ siècle, et en particulier dans la période 1830-1870, la France constitue un objet de débat récurrent parmi les intellectuels britanniques. Les changements de régime, les révolutions, le bonapartisme et le second Empire, la politique extérieure française, les mœurs, etc., ont été discutés par les "moralistes publics", c'est-à-dire un groupe d'hommes qui se rencontraient, correspondaient, s'affrontaient parfois, publiaient des articles dans des revues réservées aux élites, écrivaient des pamphlets, voire faisaient de la politique pendant quelque temps. L'historien whig T. B. Macaulay, le penseur et historien catholique Lord Acton, les essayistes Thomas Carlyle et Matthew Arnold, l'économiste Nassau William Senior, et surtout le journaliste et pamphlétaire Walter Bagehot, ainsi que le philosophe et économiste John Stuart Mill, constituent, avec quelques auteurs de moindre importance, une génération de penseurs. Tous sont des libéraux, qui ont en outre en commun d'avoir étudié la France dont ils ont une connaissance livresque et souvent directe, par de longs séjours sur le continent; ils sont parfois liés à des intellectuels français, comme Guizot ou Tocqueville. C'est à la production de ces auteurs sur la France et les Français que Georgios Varouxakis, un spécialiste de science politique, consacre cet ouvrage.

Le propos est divisé en cinq chapitres. Dans un premier temps, l'auteur campe les hommes dont il a étudié les textes. Il évoque l'ethnocentrisme qui caractérise l'époque victorienne, et la place qu'occupe la France dans sa définition : les penseurs victoriens sont convaincus de l'existence de "caractères nationaux", "la moins changeante des choses dans monde qui évolue et change en permanence" (Bagehot) ; cette certitude qui croit s'enrichir des théories darwiniennes, diffusées à partir de la fin des années 1850 . Certes, il n'était guère aisé de manier avec cohérence des catégories telles que "Gaulois", "Latins", "Celtique" (d'Irlande, d'Écosse, du pays de Galles, voire de France), "Germain", etc. ; mais un point ressortait toujours : les Anglo-Saxons étaient le peuple 
qui bénéficiait des plus grandes qualités, en particulier l'aptitude à la liberté. Ainsi, ces théories sont indissociables du patriotisme. Mais si tous les penseurs évoqués sont patriotes, la forme que prend leur attachement à l'Angleterre victorienne varie. Mill et Arnold, francophiles, "patriotes cosmopolites" selon le mot de G. Varouxakis, s'attachent à montrer aux Anglais ce qu'ils auraient à gagner à emprunter à la France et aux Français.

Une des prétendues "vertus" de la France était son caractère "civilisé" ; c'est l'objet du deuxième chapitre de l'ouvrage, qui décrit la confusion qui régnait autour de la notion de "civilisation". Quand Thomas Macaulay, le libre-échangiste Richard Cobden, le social-chrétien Charles Kingsley, etc., expliquaient que l'Angleterre avait la primeur de la "civilisation", les positivistes britanniques comme Frederic Harrison répliquaient que c'est Paris qui en était le centre ; les uns et les autres mettaient en fait des choses différentes derrière le même mot. Pour Mill, reprenant Guizot (la civilisation est le progrès humain en général), la France est plus civilisée, car l'intellect y est plus valorisé, les gens y sont plus heureux car moins commerçants, et moins enclins à se concentrer sur les applications pratiques uniquement. Pour Arnold comme pour d'autres également, la France est plus civilisée car les Français ont "l'esprit de société" et celui d'égalité ; l'attachement des Alsaciens germaniques à la France n'en était-il pas le meilleur symbole ? À l'inverse, leurs détracteurs rattachaient la civilisation au progrès commercial, économique, social, et plaçaient sur ce plan-là, sans hésiter, la France derrière l'Angleterre et "ses docks, ses chemins de fer, ses canaux". Dans un troisième chapitre, l'auteur passe en revue la réception d'événements français outre-Manche. La révolution de 1830 suscite une grande sympathie, voire de l'enthousiasme, et la monarchie de Juillet bénéficie parfois de jugements favorables, jusqu'à ce que des crises diplomatiques, notamment l'affaire des Mariages espagnols en 1846, ne la discréditent outre-Manche. Les réactions à la révolution de 1848 et à la Seconde République sont plus controversées, reproduisant les clivages déjà évoqués : Mill et Arnold sympathisent avec la révolution, Lamartine et le gouvernement provisoire, et saluent l'intelligence de masses "mues par les idées", tandis que toute une école de pensée fustige l'incapacité française au gouvernement stable et libre. Aucun ne défend réellement le "droit au travail" ni les "républicains rouges" des journées de Juin. Le coup d'État et le Second Empire rallient cependant les plus francophiles comme Mill au camp des critiques d'un peuple incapable de se gouverner librement. Non seulement l'esprit français est trop mené par des abstractions, mais les Français sont enclins à suivre quiconque leur promettra la gloire et la grandeur dans l'expansion, quel qu'en fût le prix sur le plan des libertés. Comme les Irlandais, les Français aiment à "personnaliser le gouvernement, à le considérer comme le régime d'un homme [...] et à attendre de lui qu'il guide, dirige et gouverne tout" (Acton). Bagehot donne alors ce qui est, aux yeux de G. Varouxakis, la forme la plus accomplie de l'analyse des comportements français : l'excitabilité, l'inaptitude au compromis, au régime parlementaire, à la liberté, auxquels il faut un régime fort. La Commune --que seuls, parmi les intellectuels anglais, les positivistes défendront-- ne fera qu'enraciner chez lui cette conviction.

Ce rapport entre caractère national français et politique française est ensuite étudié par Varouxakis. Les Français, aux yeux de francophobes comme Carlyle, mais aussi de bien d'autres, "parlent toujours, gesticulent toujours", copulent trop, sans parler d'autres vices comme celui de "manger, manger à n'en plus finir". La légèreté proverbiale des Français, leur inconstance, leur versatilité sont censées expliquer les 
défauts de leur système politique. Dans les années 1860, les Français sont de plus en plus comparés aux Allemands, en général à l'avantage de ces derniers, loués pour leur énergie, leur honnêteté, leur moralité. Même un ancien francophile comme Matthew Arnold fustige "la dégénérescence de la race française", idée à laquelle Mill s'oppose. Enfin, la politique étrangère n'étant plus faite par les rois et les ministres, mais par les opinions publiques (Senior), la politique extérieure française souffre des même défauts que la politique intérieure. Les Français sont orgueilleux, vaniteux, belliqueux, excitables, volatils, vindicatifse à l'égard des Anglais, irrespectueux des traités internationaux, des lois et conventions, ambitieux et expansionnistes. Ces thèmes sont déclinés lors de chacune des crises diplomatiques, selon des modalités qu'étudie un cinquième et dernier chapitre. La crise du Proche Orient en 1840, la révolution de 1848 et le Manifeste de Lamartine, les peurs de l'invasion, notamment sous Louis-Napoléon Bonaparte, et la guerre franco-prussienne de 1870 sont ainsi évoquées. Aboutissement logique de l'évolution des 20 années précédentes : la grande majorité des penseurs étudiés soutiennent la Prusse, après que Mill lui-même eut soutenu l'Autriche contre la France dans les affaires italiennes. En conclusion, G. Varouxakis cherche des échos de ces positions dans le débat contemporain, en particulier sur le gaullisme comme un phénomène français.

Le propos de l'auteur est parfois plus descriptif qu'analytique, et on peut regretter qu'il n'ait pas poussé la réflexion, parfois esquissé, sur les mécanismes des courants de pensée décrits. Car les stéréotypes et représentations évoqués nous instruisent, sur les conceptions politiques domestiques en vigueur dans Grande-Bretagne victorienne, plus encore que sur l'étranger. Et il aurait été intéressant d'étudier comment se construit en creux, dans ces représentations de la France et des Français, une représentation de l'Angleterre et des Anglais. Mais cela s'éloignerait un peu du propos de l'auteur dans un ouvrage concis, qui garde le mérite important de confronter les textes d'une douzaine d'auteurs prolixes, textes de nature différente (articles, ouvrages, pamphlets, correspondance), et publiés sur une période de quelque 40 années. 